\title{
LENGTH OF ORBITAL MARGINS OF DRY SKULLS IN A LOCAL PAKISTANI POPULATION
}

\author{
Ammara Rasheed, Mohtasham Hina, Raafea Tafweez Kuraishi \\ Correspondence to Ammara Rasheed, Dept. King Edward medical university, Lahore, Pakistan. Email \\ ammararasheed@ymail.com
}

\begin{abstract}
Orbit is an important bony cavity which lodges eyeball and associated structures for our fundamental sense of vision. Knowledge regarding accurate morphometric measurements of its margins and depth will help in diagnosis and treatment plans of various optic functions. Previous studies showed racial differences in different populations we want to collect data in local population of Asian region as we are lacking data in this region. This study was carried out on 64 bony orbits of 32 dry Asian human skulls. Measurements from right and left bony orbits were taken by digital vernier calipers in millimeters and entered in SPSS 18.0 for calculation of mean and standard deviation. Results were obtained from different orbital margins. Right superior, inferior, medial and lateral orbital margins showed results as $31.30 \pm$ $2.329 \mathrm{~mm}, 33.59 \pm 3.35 \mathrm{~mm}, 29.57 \pm 2.28 \mathrm{~mm}$ and $28.37 \pm 2.023 \mathrm{~mm}$ respectively. While left superior, inferior, medial and lateral orbital margins were $30.944 \pm 2.1080 \mathrm{~mm}, 31.19 \pm 2.54 \mathrm{~mm}, 29.567$ $\pm \quad 2.36 \mathrm{~mm}$ and $28.14 \pm 2.286 \mathrm{~mm}$ respectively. Right sided depth from optic canal to frontomaxillary suture was $41.40 \pm 2.88$ and left sided depth was $39.93 \pm 3.33 \mathrm{~mm}$. Data collected in Asian population showed differences from other races. This study covers important area regarding helpful in surgeries of this region as precise measurements could avoid injuries and postoperative complications.
\end{abstract}

Key Words: Orbital Margin, Pakistan

\section{INTRODUCTION}

The orbit is a bony socket on either side of the nose, in which very important special sense organ eye ball and its appendages lie (Standring, 2016). It is an important gateway which is connected to central nervous system, nose, paranasal sinuses and face, because of vessels and nerves which pass through its various foramina (Di Somma et al; 2017). It has important fissures and foramina including supraorbital and infraorbital foramen, superior orbital and inferior orbital fissures, optic canal and small ethmoidal foramen (Moore $\mathrm{KL}$ et al; 2013). It is like a four-sided pyramid comprising medial, lateral, superior, inferior margins with base and apex (Sinnatamby, 2011). Knowledge regarding accurate morphometric measurements of its margins and depth will help in diagnosis and treatment plans of various optic functions (Chrcanovic et al; 2011). So, surgeons need to have a proper understanding of the human orbital structure, its relationship with both intra- and extracranial structures, and associated key surgical and anatomical landmarks (Munguti et al; 2012). Modern facial surgical techniques require details regarding measurements of various concerned reference points of orbit. It is therefore important to consider the lengths of the superior and inferior orbital depths during deep orbit surgical operations in order not to damage the optic nerve and associated vessels (Huanmanop et al; 2007).

The aim of study was to collect data of bony orbits from our local population because racial differences exist as shown by previous studies (Yoon et al; 2016) and (Radunovic $M$ et al; 2018). As we lack data from our region in Pakistan, this study will be helpful in various techniques of anesthesia and in maxillofacial, orbital and plastic surgical procedures to reduce the risk of various complications 


\section{MATERIALS AND METHODS}

This study was carried out in Anatomy department of King Edward Medical University, Lahore. Measurements from all the four orbital walls of both right and left sides i.e superior, inferior, medial and lateral from 64 bony orbits (32 dry human skulls) were taken by the digital vernier calipers in millimeters. These measurements were taken twice by all authors to reduce the chance of error. For superior orbital wall distance was taken from supraorbital foramen to closest margin of supraorbital fissure. For inferior wall distance from infraorbital foramen to closest margin of infraorbital fissure was measured. For medial wall, distance was taken from posterior lacrimal crest to posterior ethmoidal foramen. For lateral orbital wall, from frontozygomatic suture to close margin of inferior orbital fissure, distance was measured. Right and left sided depths from optic canal to frontomaxillary suture was also measured.

\section{RESULTS}

Mean and standard deviation calculated for right and left orbital walls and depths from optic canal to frontomaxillary suture, were given in table below. Results showed no significant difference of measurements between right and left sides of orbits. The average distance of right superior orbital wall between supraorbital fissure to closest margin of superior orbital fissure was $31.30+/-2.329 \mathrm{~mm}$ and left superior orbital margin was $30.94+/-2.10 \mathrm{~mm}$. The average lengths for right and left inferior orbital wall between infraorbital foramen to closest margin of inferior orbital fissure were $33.588+/-3.34$ $\mathrm{mm}$ and $31.189+/-2.537 \mathrm{~mm}$. For right and left medial orbital walls, distances from posterior lacrimal crest to posterior ethmoidal foramen were 29.57 +/- $2.278 \mathrm{~mm}$ and 29.56 +/- 2.35 $\mathrm{mm}$. And right and left lateral orbital walls showed lengths of $28.374+/-2.02 \mathrm{~mm}$ and 28.14 $+/-2.28 \mathrm{~mm}$. Right and left sided depths from optic canal to frontomaxillary suture were $41.395+/-2.88 \mathrm{~mm}$ and $39.93+/-3.33 \mathrm{~mm}$, respectively.

Table 1 : Different orbital measurements

\begin{tabular}{|l|l|l|}
\hline \multicolumn{1}{|c|}{} & $\begin{array}{l}\text { Std. Deviation } \\
\text { (Mean) }\end{array}$ & p-value \\
\hline $\begin{array}{l}\text { Pair 1 right superior orbital margin } \\
\text { Left superior orbital margin }\end{array}$ & $2.33(31.3)$ & 0.5229 \\
\hline Pair 2 right inferior orbital margin & $2.11(30.9)$ & \\
Left inferior orbital margin & $3.3(33.6)$ & 0.0020 \\
\hline $\begin{array}{l}\text { Pair 3 right medial orbital margin } \\
\text { Left medial orbital margin }\end{array}$ & $2.5(31.2)$ & \\
\hline Pair 4 right lateral orbital margin & $(29.5700)$ & 0.9962 \\
Left lateral orbital margin & $2.4(29.6)$ & \\
\hline Pair 5 right sided depth from optic canal to FM & $2.0(28.4)$ & 0.6663 \\
suture & $2.3(28.1)$ & \\
Left sided depth from optic canal to FM suture & 2.87991 & 0.0645 \\
& $(41.3959)$ & \\
\hline
\end{tabular}




\section{DISCUSSION}

Table 2: Comparison of orbital measurements in different Population

\begin{tabular}{|l|l|l|l|l|l|l|}
\hline Author & Present & $\begin{array}{l}\text { Karakas et } \\
\text { al. }\end{array}$ & $\begin{array}{l}\text { Haunmanop } \\
\text { et al. }\end{array}$ & $\begin{array}{l}\text { Munguti et } \\
\text { al. }\end{array}$ & $\begin{array}{l}\text { Hawang et } \\
\text { al. }\end{array}$ & $\begin{array}{l}\text { Fathy A } \\
\text { et al }\end{array}$ \\
\hline Population & Pakistani & Caucasian & Thai & Kenyan & Korean & Egyptian \\
\hline Supraorbital wall & 31.12 & 45.7 & 39.8 & --- & 40.0 & 46.23 \\
\hline Infraorbital wall & 32.388 & 31.9 & 40.2 & 23.60 & 26.4 & 24.62 \\
\hline Medial orbital wall & 29.56 & 35.6 & 36.0 & ---- & 31.7 & 35.39 \\
\hline $\begin{array}{l}\text { Lateral orbital } \\
\text { wall }\end{array}$ & 28.25 & 33.4 & 23.95 & ---- & 34.3 & 29.08 \\
\hline $\begin{array}{l}\text { Right sided depth } \\
\text { of orbit from FM } \\
\text { suture to optic } \\
\text { canal }\end{array}$ & 41.39 & ----- & ---- & ---- & ---- & --- \\
\hline $\begin{array}{l}\text { Left sided depth } \\
\text { of orbit from FM } \\
\text { suture to optic } \\
\text { canal }\end{array}$ & 39.93 & ---- & ---- & ---- & & \\
\hline
\end{tabular}

Orbital measures are very important during reconstructive procedures as well as during administration of periorbital anesthesia. Measurements of all the four orbital margins and depth from optic canal to frontomaxillary suture is crucial for safety of neurovascular structures of orbit during various surgical procedures. Orbital measurements and depth seem to be dependent on population studied because previous studies showed differences in orbital measurements for various ethnic groups.

In our present study there was no significant difference between right and left sides of skull. There is ethnic variation as shown by previous studies. Study conducted by Karakas et al. in Caucasians population showed difference in orbital measurements as for superior, inferior, medial and lateral walls were $45.7+/-3.6 \mathrm{~mm}$, $31.9+/-3.9 \mathrm{~mm}, 35.6+/-2.5 \mathrm{~mm}$ and $33.4+/-$ $3.1 \mathrm{~mm}$ respectively. Study on kenyian population showed inferior orbital wall length as $23.825 \mathrm{~mm}$ (right orbit); $23.378 \mathrm{~mm}$ (left orbit) conducted by Munguti et al. Another study on Thai population showed measurements of orbital margins of superior, inferior, medial and lateral as follows, $39.8+2.3 \mathrm{~mm}$ (left ) and $40.2+$ $2.4 \mathrm{~mm}$ (right), $21.9+2.1 \mathrm{~mm}$ (left) and $21.5+$ $1.8 \mathrm{~mm}$ (right), $35.6+2.4 \mathrm{~mm}$ (left) and $36.4+$ $2.6 \mathrm{~mm}$ (right), $23.2+2.3 \mathrm{~mm}$ (left) and $24.7+$ $2.1 \mathrm{~mm}$ (right) respectively by Huanmanop et al. Fathy $A$ et al in his study showed orbital wall measurements in Egyptian adults as 46.23, 24.62 , 35.39, 29.08mm for superior orbital, inferior orbital, medial and lateral orbital walls.

In conclusion, measures from various reference points were obtained for measuring orbital walls. Although there is no significant side difference in data collected but there is difference in measurements among different races. These findings can be considered as a guide for the orbital surgeon to aid in planning operations and minimizing complications. These variations should be considered during surgeries on respective region. Many important anatomic landmarks which are short of in our present study need to be measured and surgically evaluated in future research. 


\section{REFERENCES}

1- Standring S. 2016. Gray's Anatomy. Ed 41. The orbit and Accessory visual apparatus. 655-657.

2- Di Somma A, Andaluz N, Cavallo LM. 2017. Endoscopic transorbital superior eyelid approach: anatomical study from a neurosurgical perspective. Journal of Neurosurgery, 15:1-14.

3- Moore KL, Dalley AF, Agur AMR. 2013. Clinical Oriented Anatomy. Ed 7. Head and Neck. Pg 211-213.

4- Sinnatamby CS. 2011. Last's Anatomy Regional and Applied. Ed 12. Orbit and eye. 397-398.

5- Chrcanovic BR, Abreu MH, Custódio AL. 2011. A morphometric analysis of supraorbital and infraorbital foramina relative to surgical landmarks. Surgical and Radiological Anatomy, 33(4):329-35.

6- Munguti J, Mandela P, Butt F. 2012. Referencing orbital measures for surgical and cosmetic procedures. Anatomy Journal of Africa, 1(1):40-45.

7- Huanmanop T, Agthong S, Chentanez V. 2007. Surgical anatomy of fissures and foramina in the orbits of Thai adults. Journal of Medical Association of Thailand, 11:2383-91.

8- Yoon J, Pather N. 2016. The orbit: A re-appraisal of the surgical landmarks of the medial and lateral walls. Clinical Anatomy, 29(8):998-1010.

9- Radunovic M, Vukcevic B, Radojevic N, Vukcevic N, Popovic N, Vuksanovic-Bozaric A. 2018. Morphometric characteristics of the optic canal and the optic nerve. Folia Morphologica, 14.

10- Hwang, Kun, Baik, Sang Ho. 1999. Surgical Anatomy of the Orbit of Korean Adults. Journal of Craniofacial Surgery, 10(2):111-115.

11- Karakas P, Bozkir MG, Oguz O. 2002. Morphometric measurements from various reference points in the orbit of male Caucasians. Surgical and Radiological Anatomy, 24:358-362.

12- Fathy AF and Dalia Mandour. 2014. Morphometric analysis of the orbit in adult Egyptian skulls and its surgical relevance. European Journal of Anatomy, 18(4):303-315. 